\title{
Appendix 4: Roman Emperors and Family Members Praised at Delphi by Citizens of Delphi and the Amphictyony
}

\begin{tabular}{ll}
$\begin{array}{l}\text { Emperors } \\
\text { (and members of their family) }\end{array}$ & No. of statues \\
\hline Augustus & $0+4$ children of M. Vipsanius Agrippa \\
Tiberius & 1 \\
Caligula & $0+$ Iulia Drusilla \\
Claudius & $1+1$ (him or Caligula) \\
Nero & $1+$ Agrippina the Younger \\
Titus & 1 \\
Nerva & 1 \\
Trajan & 2 \\
Hadrian & 4 \\
Antoninus Pius & $1+$ Faustina the Elder \\
Marcus Aurelius & $1+$ Faustina the Younger \\
Commodus & 1 \\
Severus & 1 \\
Alexander & 1 \\
Gordian III & 1 \\
Valerian & 1 \\
Gallienus & 1 \\
Carus & 1 \\
Constantius I & 1 \\
Constantine the Great & 1 \\
Constans I & Valentinian I \\
Valens & 1 \\
\hline & \\
\hline
\end{tabular}

